\title{
PAHs IN FLY ASH FROM LIGNITE COMBUSTION
}

\section{Stefanova M. ${ }^{1}$, Marinov S. P. ${ }^{1}$, Gonsalvesh L. ${ }^{1}$, Mastral A. ${ }^{2}$, Callen M. ${ }^{2}$, and Gadjanov P. ${ }^{3}$}

\author{
${ }^{1}$ Institute of Organic Chemistry, Bulgarian Academy of Science, Sofia 1113, BULGARIA \\ maia@orgchm.bas.bg \\ ${ }^{2}$ Instituto de Carbochimica CSIC,50015-Zaragoza, SPAIN \\ ${ }^{3}$ Technical University, Sofia 1750, BULGARIA
}

\begin{abstract}
This paper describes state-of the art for isolation and determination of polycyclic aromatic hydrocarbons (PAHs) in fly ash from lignite combustion in Maritza East Thermal Power Plant, Bulgaria. Total sum of $\sim 17$ microg $/ \mathrm{kg}$ solid by-product PAHs was determined. The profile of PAHs distribution according to the number of aromatic rings in the molecule $(R)$ was determined. Organic extracts were mainly composed by PAHs, their alkylated homologues and heteroatom containing counterparts with dominance of three/four cyclic aromatic compounds. Respectively, relative carcinogenic potency values for PAHs compared to Benzo[a]pyrene with $T E F_{E P A}=1$ was not high - 0,07385.

Seventeen PAHs, some of them in the list of USEPA for priority pollutants with expressed carcinogenic/mutagenic potential, were identified and quantified by mass spectroscopy (GC/MS/MS) and d-PAHs as internal standards. Determined values for contents of PAHs under regulation were lower than their backgrounds in Bulgarian soils. Nevertheless PAHs in combustion fly ash should be monitored because of high solid by-products annual production and problems of reuse.
\end{abstract}

Key words: coal, fly ash, PAHs.

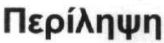

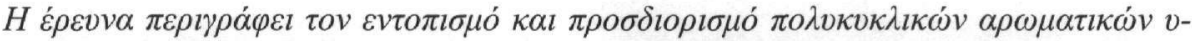

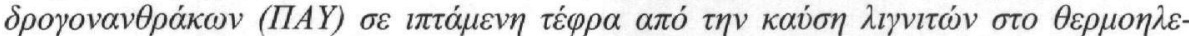

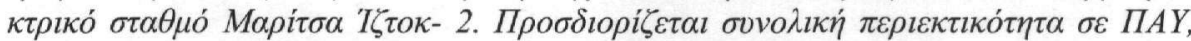

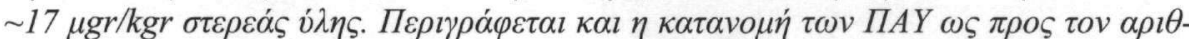

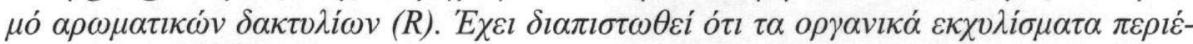

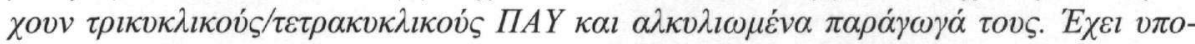

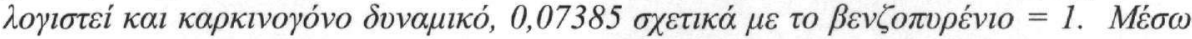

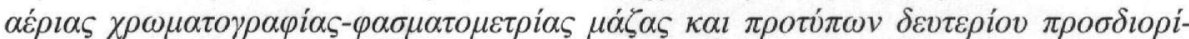

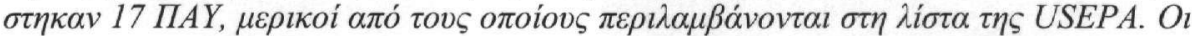

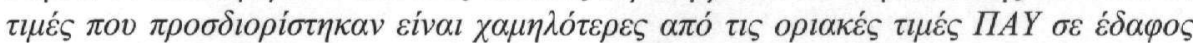

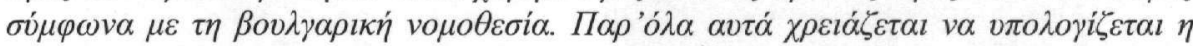

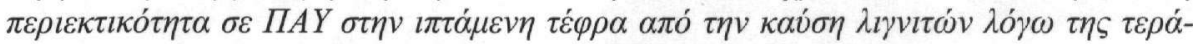

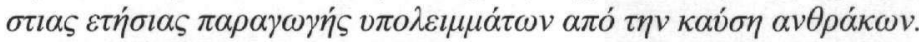

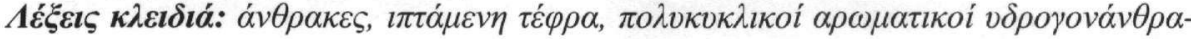
$\kappa \varepsilon \varsigma$. 


\section{Introduction}

The utilization, or proper disposal, of coal combustion by-products is a topic of interest in all countries using coal for power generation. The main problem to solve is with fly ash exploitation (Hower 2005). Pulverized coal-fired combustion of Maritza-East lignite in Thermal Power Plants (TPPs) is the main technology of electricity production in Bulgaria. During lignite combustion a broad range of harmful species and gases are generated $\mathrm{CO}_{2}, \mathrm{SO}_{2}, \mathrm{NO}_{\mathrm{x}}$ and particular matter (PM) have been monitored for a long time (Stoimenova 2002). The organic compounds formed during combustion have obtained less attention. Presently the situation is going to be changed as organic polluters, i.e. PAHs, furanes, chlorinated species, so called VOCs (Volatile Organic Compounds), will be the target of special legislation. At the moment it is a Normative Proposal at the European Parliament (Proposal 2003/164COD). Due to the specific quality of Maritza-East lignite the group of TPPs in the region is a polluter of the environment in Balkan Peninsula.

At present Wet Limestone desulphurisation method is applied in Maritza-East TPPs complex. The method assures to meet the requirements for PM content and gas emissions. Nevertheless, the three existing TPPs with total capacity of $2400 \mathrm{MW}$ are among the 15 significant polluters of the environment in Europe. At the same time the national energy strategy foresees to erect new energy units of up to $1500 \mathrm{MW}$ total till the year 2020 using lignite coal. The main problem with the present and future operation of Maritza-East TPPs is to reduce the "trans" boundary emissions and to reach the European legislation norms.

On the other hand, Maritza-East lignites are the basic domestic fuel used for house-hold briquette production. Our ongoing research on the pyrolysis of commercially available briquettes in laboratory equipment revealed high SO2 emissions. In the flue gases a broad range of organic compounds were identified as well. Lower molecular sulphur containing ones (thiols, organic sulphides, polysulphides, thiophenes) and typical products of coal thermal destruction could be regarded as VOC, harmful for the ambient air (Marinov et al. 2006).

The Wet Limestone technology has been widely used throughout the world in an effort to reduce acid rain from sulphur oxide emission. Although the technology successfully reduces $\mathrm{SO}_{2}$ emission it creates enormous million metric tons of by-product generated in power stations. For example, Maritza-East-2 TPP, with combustion efficiency $85 \%$ and 3-4 \% of unburnt fuel, consumes 350 tons lignite per hour with $50 \mathrm{t} / \mathrm{h}$ by-products, i.e. $45 \mathrm{t} / \mathrm{h}$ fly ash and $5 \mathrm{t} / \mathrm{h}$ bottom ash (slag). Respectively, 80000 tons of fly ash and 9700 tons of slag are monthly generated. Waste territories are covered by dumps and are sources for particular matter as well as of leaching. Before to reuse these waste materials they should be properly characterized. There is a suite of publications of Vassilev (2005) devoted to the mineral matter of ashes from Bulgarian power stations while the organic matter content is somewhat neglected. The overview on published data pointed out that sufficient portion of PAH could be adsorbed/absorbed on the solid products, i.e. fly ash and slag. Respectively, organic compounds might have an important impact on environment and research on them in combustion wastes is necessary.

Coal combustion is one of the biggest sources of VOCs in the environment. The interest on the polycyclic aromatic compounds (PAC) in combustion flue gases is provoked by their carcinogenic potential. According to the international standards (USEPA), the following polycyclic aromatic hydrocarbons $(\mathrm{PAH})$ are considered as priority pollutants: acenaphthene, fluorene, anthracene, pyrene, benzo[a] anthracene, chrysene, benzo[a]pyrene, benzo[k]fluoranthene, perylene, dibenzo[a,h]anthracene, coronene, etc. Depending on their molecular mass PAH can be concentrated in the gas phase (<6-ring PAH's), in the solid phase ( $>6$-ring PAH's) or in both phases (4and 5-ring PAHs). These organic compounds are considered extremely toxic. They are generated throughout the combustion process and their concentrations depend on technological parameters, i.e. combustion temperature, coal rank, fluidizing agent, oxygen excess, etc. PAHs emitted from FBC were discussed in the review of Mastral and Callen (2000). Herein, PAHs origin, sampling and analytical procedures for determination were commented. Finally, the influence of the fuel, the 
combustion type and the combustion variables affecting PAH formation and distribution in solid/gaseous phase were under consideration. Situation with polycyclic aromatic compound emissions during coal combustion is additionally complicated when low rank coals with high sulphur contents are subjected to thermal treatment. Unfortunately, TPPs in Maritza-East region are supplied by low calorific with high sulphur contents Thracian lignites. In emissions from their combustion a high contents of PAH and their sulphur analogues are expected.

\section{Materials and Methods}

Fresh fly ash samples after electrical precipitator of Maritza-East-2 TPP were collected. The samples $(25-30 \mathrm{~g})$ were dried, crushed, sieved $(<0.071 \mathrm{~mm})$ and carefully stirred. Analysis was performed in duplicate. Samples were exhaustively Soxhlet extracted for 40 hours by methylenechloride. Total extracts were concentrated at reduced pressure and subjected to column separation The protocol of aromatic fraction isolation is described in Mastral et al (2001). Fractions were qualitative analyzed by GC/MS and PAHs were quantified by GC/MS/MS

For GC-MS study Hewlett-Packard 6890 gas chromathograph equipped with 5973 MS detector was used. Column HP-5 (30m lenght, $0.25 \mathrm{~mm}$ ID amd $0.25 \mathrm{~mm}$ film thickness). Program: 0.5 ${ }^{\circ} \mathrm{C} / \mathrm{min}$ up to $85^{\circ} \mathrm{C}$, then $20^{\circ} \mathrm{C}$ up to $200{ }^{\circ} \mathrm{C}$ and finally $5{ }^{\circ} \mathrm{C} / \mathrm{min}$ up to $320^{\circ} \mathrm{C}$.

Previous to the sample quantification by external standard calibration, standard solutions containing the total of $16 \mathrm{PAH}$ were prepared at different concentrations by appropriate dilution and injection into the GC/MS/MS for determining the linearity. Resin blanks were also prepared for determining detection limits.

Samples were analyzed by GC (Varian GC 3800) equipped with a low bleeding fused-silica capillary column CP-Sil $8 \mathrm{CB}$ (length: $60 \mathrm{~m}$, inner diameter: $0.25 \mathrm{~mm}$; thickness: 0.25 microm) coupled to MS/MS detector (Saturn 2200) operating in electron impact mode (70 eV).

Table 1 -PAHs listed by USEPA as priority pollutants and their TEF $_{\text {EPA }}$ values

\begin{tabular}{lccc}
\multicolumn{1}{c}{ PAH } & Formula & Molecular mass & TEF $_{\text {EPA }}$ * value \\
\hline Fluorene & $\mathrm{C}_{13} \mathrm{H}_{10}$ & 166 & n.a. \\
\hline Anthracene & $\mathrm{C}_{14} \mathrm{H}_{10}$ & 178 & 0.0005 \\
\hline Fluoranthene & $\mathrm{C}_{16} \mathrm{H}_{10}$ & 202 & 0.05 \\
\hline Acenaphthene & $\mathrm{C}_{12} \mathrm{H}_{10}$ & 154 & n.a. \\
\hline Chrysene & $\mathrm{C}_{18} \mathrm{H}_{12}$ & 228 & 0.03 \\
\hline Pyrene & $\mathrm{C}_{16} \mathrm{H}_{10}$ & 202 & 0.001 \\
\hline Benzo[ghi]perylene & $\mathrm{C}_{22} \mathrm{H}_{12}$ & 276 & 0.02 \\
\hline Benzo[k]fluoranthene & $\mathrm{C}_{20} \mathrm{H}_{12}$ & 252 & 0.05 \\
\hline Benzo[a]anthracene & $\mathrm{C}_{18} \mathrm{H}_{12}$ & 228 & 0.005 \\
\hline Indeno[1,2,3-c,d]-pyrene & $\mathrm{C}_{22} \mathrm{H}_{12}$ & 276 & 0.1 \\
\hline Benzo[b]fluoranthene & $\mathrm{C}_{18} \mathrm{H}_{10}$ & 226 & 0.1 \\
\hline Dibenzo[a,h]anthracene & $\mathrm{C}_{22} \mathrm{H}_{14}$ & 278 & 1.1 \\
\hline Benzo[a]pyrene & $\mathrm{C}_{20} \mathrm{H}_{12}$ & 252 & 1.0
\end{tabular}

n.a. - not available; * - relative potency of individual PAH compared to Benzo[a]pyrene

The temperature time program at the working conditions of the GC/MS/MS was the following: 60 ${ }^{\circ} \mathrm{C}$ isotherm for $1 \mathrm{~min}, 10^{\circ} / \mathrm{min}$ till $300{ }^{\circ} \mathrm{C}$ and isotherm for 15 minutes. The injector was kept following the program: $60{ }^{\circ} \mathrm{C}$ for $0.5 \mathrm{~min}, 100{ }^{\circ} \mathrm{C} / \mathrm{min}$ till $330^{\circ} \mathrm{C}$ and isotherm for 45 minutes. Helium was used as carrier gas and transfer line was heated at $280^{\circ} \mathrm{C}$. In all cases, 1 microl of sample was injected in split less mode (1/50, split valve closed for $3.5 \mathrm{~min})$. 
In order to check the analytical accuracy and precision, analyses of an appropriate standard reference material (SRM 1944) of National Institute of Standards and Technology (NIST) were carried out. Measured values were satisfactorily comparable to certified values with a accuricy between $0.2 \%$ (for.Benzo(k)fluoranthene) and $22 \%$ for all compounds except Naphthalene, $38 \%$.

$\mathrm{B}[\mathrm{a}] \mathrm{P}$ equivalent carcinogenic power (B[a]Peq) was calculated according to the formulae proposed by Cecinato (1997)

$$
\mathrm{B}[\mathrm{a}] \mathrm{Peq}=\mathrm{B}[\mathrm{a}] \mathrm{P}+\mathrm{BFa} \times 0.07+\mathrm{B}[\mathrm{a}] \mathrm{A} \times 0.06+\mathrm{DB}[\mathrm{a}, \mathrm{h}] \mathrm{A} \times 0.6+\mathrm{IPy} \times 0.08
$$

where $\mathrm{BFa}$ is the sum of all Benzofluoranthene isomers.

\section{Results}

The total contents of organic extractable matter for fly ash were $6.25 .10^{-2} \%$. Extracts were additionally treated by metal $\mathrm{Cu}$ for sulphur elimination. Polar compounds were the predominant portion of extracted matter. Aromatics represented less than $10 \%$ of the total extracted matter.

\section{PAHs in fly ash, in microg/kg}

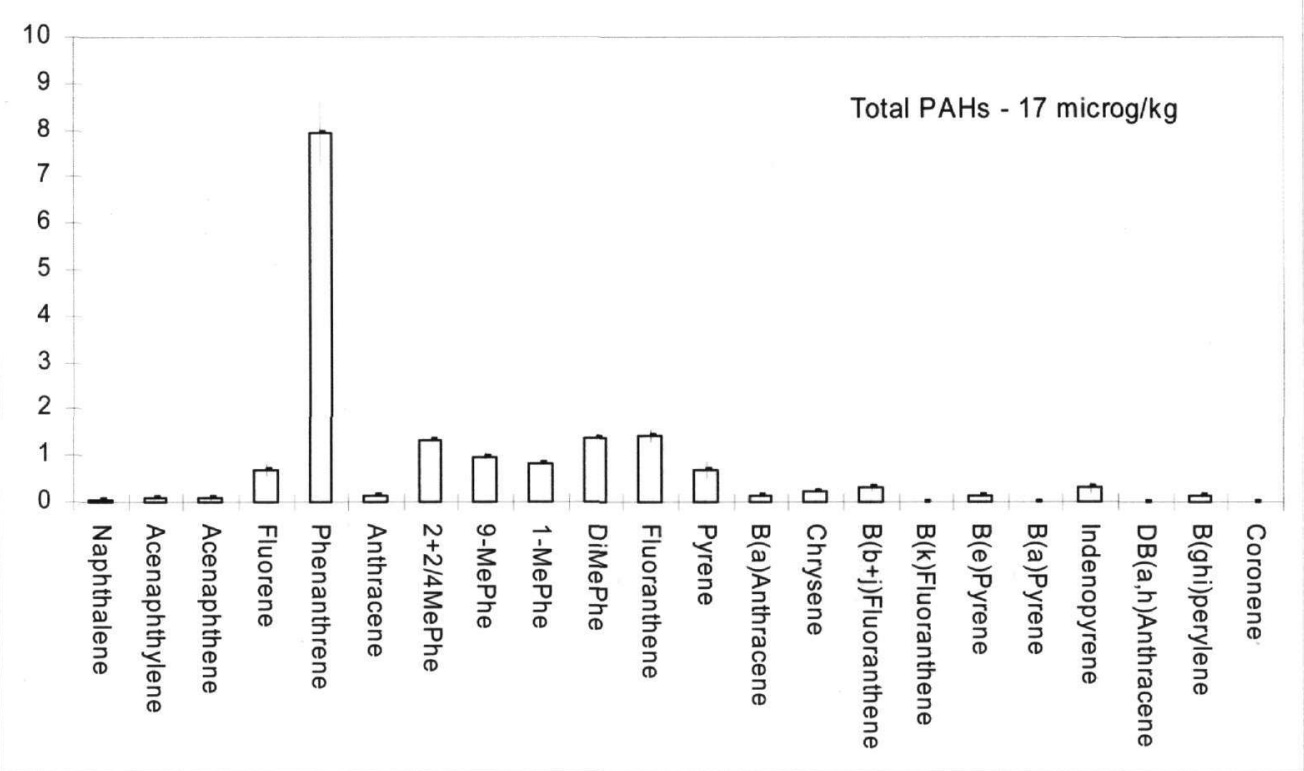

Figure 1 - PAHs contents in fly ash

The main aromatic species registered in organic extracts of fly ash were Phenanthrene and its alkylated homologs (Fig. 1). According to published date these compounds are considered as main PAHs from coal combustion (anthropogenic origin). Their high contents reflect the low degree of aromatization of the initial coal. The other compounds with three aromatic rings and same origin were Retene and Ferrugunol, both of them source-specific molecular markers. To this class of compounds could be added substituted Naphthalene (Cadalene). The terpenoids identified were tricyclic with their diagenetic, catagenetic and thermally altered products. Specially Retene was considered as the end product of resin acid alteration (abietic acid) and was a molecular indicator for combustion of coal with Gymnosperm vegetation dominance. All diterpenoids are ubiquitous compounds of vegetation (plant resins) and are typical coal biomarker (biogenic origin). 
By GC/MS/MS and application of deutereted internal standards for quantification 17 PAH, some of them in the list of USEPA for priority pollutants with expressed carcinogenic/mutagenic potential, were identified. The total contents of PAHs for fly ash under study was $17 \mathrm{microg} / \mathrm{kg}$ solid by-product with $\mathrm{B}[\mathrm{a}] \mathrm{Peq}:=0,07385$.

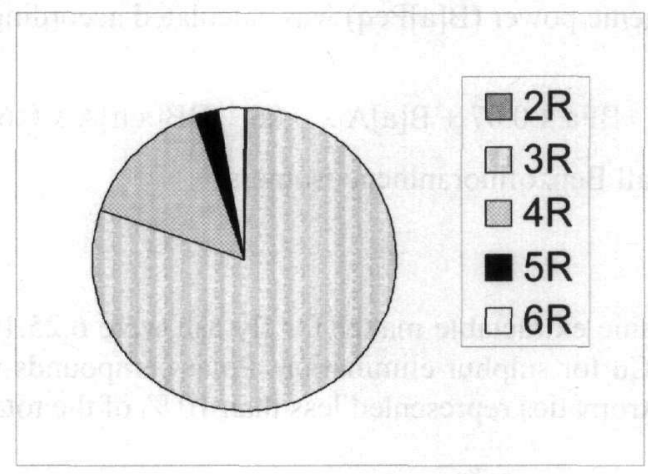

Figure 2 - PAHs rings distribution

Organic extract was characterised by the highest contents of Phenanthrene. The distribution profiles of PAH according to the number of aromatic cycles in molecules was illustrated in Fig. 2. Namely, 3R $>4 R>5 R \sim 6 R$

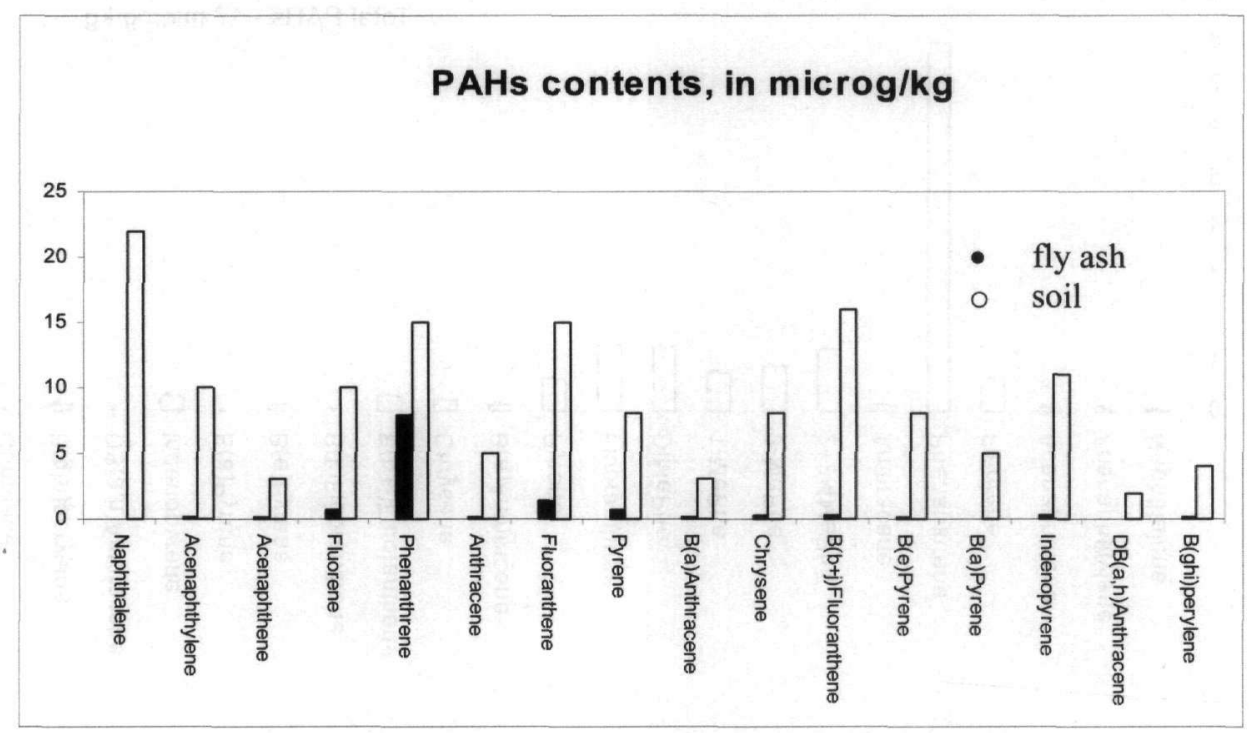

Figure 3 - PAHs in fly ash under regulation and their background for Bulgarian soils

Heavy metals (As, Cd,Cu,Cr, Ni,Pb,Zn,Hg, Co), PAHs, PCBs, petroleum products and pesticides are controlled in Bulgarian soils by legislation norms, Regulation N3 (Official Gazette, 2000, N21). In Fig. 3 are illustrated PAHs under regulation in fly ash and in soils. The values determined for PAHs in fly ash were lower the backgrounds for PAHs in Bulgaria soils.

On the other hand, published results for ecotoxicity for ashes and PMs from coal combustion pointed out that although PAHs are very toxic compounds they were not so dangerous because of their low solubility in water (Callen et al. 1998). The Microtox assay according to the standard leachate procedure determined values $>\mathrm{EC}_{50} 3000 \mathrm{mg} /$ litter, hence, solids were classified as "nonecotoxic materials". Different results should have been received if the tests were performed by 
organic extracts. Organic extractable compounds are not matter of fact as in the environment combustion wastes are stored in dumps and in the nature they are susceptible to humidity and rains, both proceeding in water. Respectively, test for toxicity proceeds in aqueous media.

Our ongoing research on PAH in solid wastes from Bulgarian lignite combustion in TPPs revealed the presence of variety of VOCs harmful for the living organisms. According to TEF $F_{E P A}$ values for aromatic compounds they were not with so highly expressed toxicity as were predominantly composed by three/four cyclic species. At the same time in the course of our investigation there was a question emerged still not received unequivocal response, namely, the recovery of PAH extraction during solid waste product analysis. Our study demonstrated once again the necessity of application of suitable cleaning technology if the legislation norms should have to be respected.

\section{Acknowledgments}

The study is done in the frame of BAS-Bulgaria/CSIC-Spain bilateral collaboration.

The financial support of Earth Sciences Project No 1312 (Ministry of Science and Education) is greatly acknowledged.

\section{References}

Callen, M.S., Maranon, E., Mastral, A.M., Murillo, R., Salgado, P., and Sastre, H., 1998. Ecotoxicological assessment of ashes and particular matter from FBC of coal, Ecotoxicology and Environmental Safety, 41, 59-61.

Cecinato, A., 1997. PAH, BaPy and N-PAH in suspended particular matter, Annali di Chimica, 87, 483-496.

Hower, J.C., 2005. Editorial Int. Ash Util. Symp. Fuel, 84, 1337.

Marinov, S.P., Stefanova, M., Stamenova, Vl., Gonsalvesh, L., Carleer, R., and Yperman, J., 2006. Sulphur analysis of household briquettes using MS and GC/MS detection system after reductive pyrolysis, J. Fuel Chem.\&Tech., 34(3), 257-264.

Mastral, A.M., and Callen, M.S. 2000. A Review of PAH Emissions from Energy Generation, Envir. Sci.\&Tech., 34, 3051-3057.

Mastral, A.M., Callen, M.S., Garcia, T., Stefanova, M., and Marinov, S.P., 2001. Polycyclic aromatic compounds in emissions of lignite Maritza-East (Bulgaria) fluidized bed combustion, J. Envir. Prot. And Ecology, 2, 19-198.

Stoimenova, A., 2002. On-line control of emissions, Engineering Review, 10, 54-64. (in Bulgarian)

Vassilev, S., 2005 Mineralogy and geochemistry of coals and their combustion solid waste products, DSc. Dissertation, CLMC-BAS, Sofia. (http://www.clmc.bas.bg/staff/ S_Vassilev/S_Vassilev.htm) 